\title{
Stimulated Formation of InGaN Quantum Dots
}

\author{
A.F. Tsatsulnikov and W.V. Lundin \\ Ioffe Institute \\ Russia
}

\section{Introduction}

Interest to the formation of QDs in wide bandgap InGaAlN system is due to several reasons. First, all layers in an InGaAlN-based heterostructures are lattice mismatched that leads to strong phase separation and QD formation even in low content thin InGaN layers. Second, QDs in the wide bandgap material have large localization energy that leads to effective localization of carriers, suppression of carrier transport toward defect areas, density of which typically is about 5-10×108 cm-3, and resulting in effective emission efficiency. Third, InGaN QDs allow expanding of emission range of InGaN-based light emitting devices. For InGaN-based light emitting diodes (LEDs) even red emission was demonstrated (Mukai et al., 1999). However, spontaneous formation of the InGaN QDs requires development of the special methods to control their structural and optical properties. In this sense detail investigations of the correlation between parameters of growth of the QDs and their properties (density, sizes, content) are important. Different approaches were studied to form InGaN QDs. Stranskii-Krastanov mechanism of InGaN QD formation was investigated in (Bai et al., 2009; Choi et al., 2007). However, specific growth conditions are required to form such QDs that can leads to worsening of structural quality of the InGaN layers and low efficiency of emission. More attention was paid to investigations of the phase separation in thin InGaN QWs at changing of the equilibrium of the epitaxial growth conditions. It was show that different growth parameters affect the properties of the InGaN QDs: annealing of the InGaN QWs after deposition (Oliver et al., 2003); growth conditions of GaN layer covering the InGaN QW (Wang et al., 2008; Wen et al., 2001); growth interruptions (GIs) after deposition of the InGaN QWs (Choi et al., 2007; Ji et al., 2004); changing of In flow or growth temperature during InGaN deposition (Kumar et al., 2008; Musikhin et al., 2002; Shim et al., 2002 ; Soh et al., 2008 ; Sun et al., 2004). Thus, formation of the InGaN QDs are depending on large number of parameters. For complex multilayer structure changing of structure design and growth conditions of under layers (below active region) can leads to changing of the active region properties. Moreover, this is correct for the effect of upper layers (above active region). This can be critical, for example, in the case of growth of monolithic white LEDs containing several InGaN QWs emitting at different wavelengths in wide region of spectrum. Besides, effect of QDs on width of emission line can improve color parameters of RGB, in particular monolithic, white LEDs.

In this paper we tried to paid attention to the results of investigations which revealed effect of different growth parameters on QD formation which usually are not widely discussed (e.g. growth pressure, growth atmosphere, layer sequence etc.) and considered features in 
an LED properties which are associated with QD formation. Effect of the QD formation on such important parameters of LEDs as wavelength and current dependencies of the emission wavelength and quantum efficiency will be shown.

\section{Technological aspects}

Epitaxial structures described below were grown by Metalorganic Vapor Phase Epitaxy (MOVPE) using systems with horizontal flow (strongly re-designed Epiquip VP-50RP) and Planetary (AIX2000HT) reactors. Gas blending units of the systems have allowed us to use hydrogen, nitrogen or their mixture at any given ratio as a carrier gas. Ammonia, trimethylgallium (TMGa), triethylgallium (TEGa), trimethylindium (TMIn), trimethylaluminum (TMAl), biscyclopentadienylmagnesium $\left(\mathrm{Cp}_{2} \mathrm{Mg}\right)$, and silane $\left(\mathrm{SiH}_{4}\right)$ were used as precursors. Reactors were equipped with a home-made in-situ optical reflectance monitoring (ORM) tools. Most of epitaxial structures were grown on (0001) sapphire substrates utilizing conventional low-temperature GaN nucleation technique. Experimental structures were characterized by various structural, electrical, and optical methods including scanning (SEM) and transmission (TEM) electron microscopy, atomic force microscopy (AFM), secondary ion mass spectrometry (SIMS), X-ray diffractometry, Hall-effect measurements, and spectroscopy of photo (PL) and electroluminescence (EL). Thickness, alloy composition and homogeneity of individual InGaN QWs, InGaN and GaN layers were investigated by Digital Analysis of Lattice Image (DALI) (Gerthsen et al., 2000; Rosenauer et al., 1996) or Geometrical Phase Analysis (GPA) (Hytch et al., 1998) of High Resolution transmission electron microscopy (HRTEM) images.

\section{Methods of QD formation}

In this chapter different methods of InGaN QD formation will be considered. We will focus on an in-situ methods of QD formation i.e. methods when QDs are formed directly during growth of InGaN QWs. These methods include different technological approaches when QD formation is stimulated by certain growth conditions, for example, growth temperature, GIs, atmosphere and pressure. On the other hand, QD formation can be stimulated by applying of special design (layer sequence) of structures.

\subsection{Effect of growth temperature}

Difference in optimal growth conditions for InGaN and GaN requires fast change of the reactor conditions when switching between these materials. In particular, GaN barriers are typically grown at temperatures at least $50-70^{\circ} \mathrm{C}$ higher than InGaN. This temperature ramp usually takes more than 20-30 sec. Thus one has to choose between growth interruption (GI) and growth at ramped conditions. Both alternatives have disadvantages. Growth during reactor conditions change generally is less reproducible. Moreover, only part of GaN barrier is grown at higher temperature. On the other hand, during GI InGaN surface is exposed to the reactor atmosphere for relatively long time that influences structure properties. There are a number of publications concerning GI-related effects (Cho et al., 2001; Daele et al., 2004). All authors describe blue shift and indium excess removal as a result of GI but general conclusions on the GI benefit is contradictory: blue shift sometimes is too high price for quality improvement. Moreover, depending on growth parameters, GI can either increase In 
nonuniformity in the InGaN layer or make this layer more uniform. Thus, effects of temperature and GIs on InGaN properties should be investigated consequently.

In the work (Musikhin et al., 2002) InGaN/GaN MQW structures were grown by applying of the method of thermocycling, when the MQW structures are formed by cycled variation of growth temperature (in temperature range between $T_{\min }$ and $T_{\max }$ ) at constant gas flows that realize periodical changes of the In content. Fig. $1(a, b)$ shows high resolution TEM (HRTEM) images of these structures grown in temperature range of $755-870{ }^{\circ} \mathrm{C}$ and $785-$ $900^{\circ} \mathrm{C}$. It is seen that distribution of the In atoms in the samples grown by this method is inhomogeneous with clearly resolved In-rich QDs. The decrease of the growth temperature results in an increase in the In concentration with average values of $18 \%$ for sample grown at high temperature and $23 \%$ for sample grown at low temperature. The total amount of InN incorporated into the QW was calculated on the basis of the maximum displacement at the top of InGaN layer yielding 1.5 monolayers (ML) and $2 \mathrm{ML}$ for samples grown at higher and lower temperatures, respectively. PL spectra of the sample grown at a lower temperature show a $200 \mathrm{meV}$ shift of the emission peak to the long wavelength side that agreed with increase in the In content.
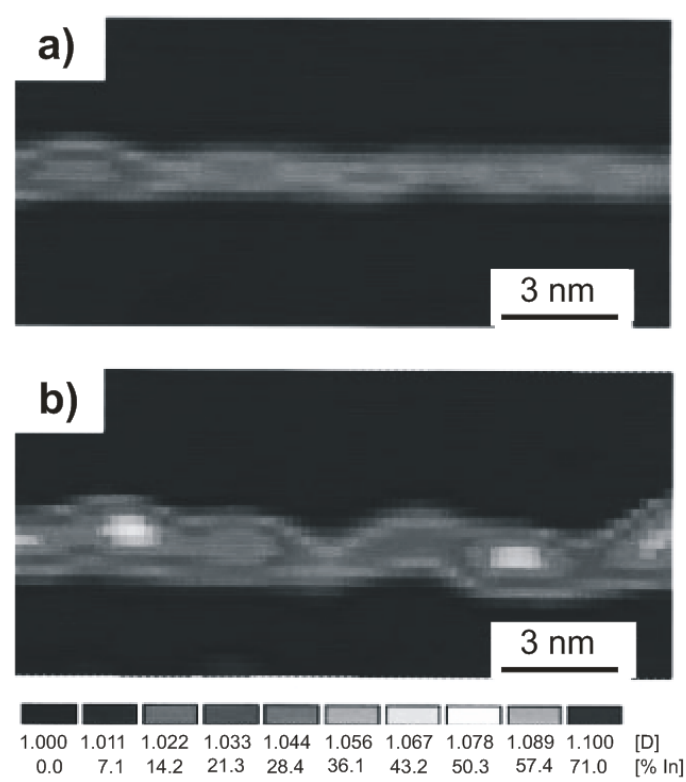
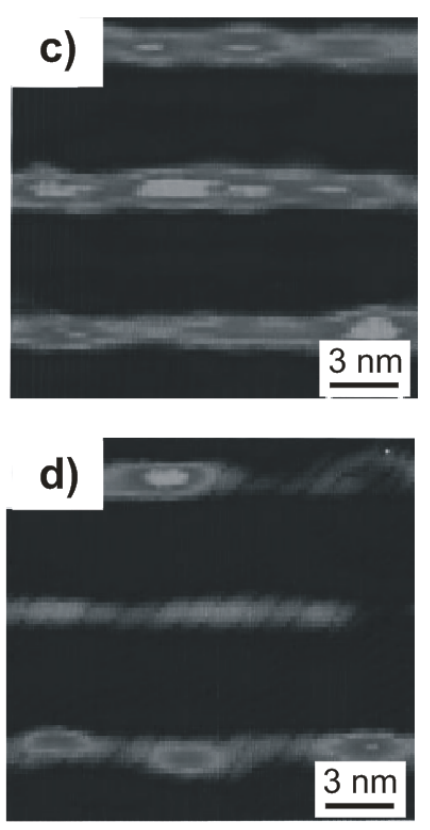

Fig. 1. Color-coded maps of the local In concentration obtained by digital analysis of highresolution transmission electron microscopy (HRTEM) images of the samples grown at lower (a) and higher (b) substrate temperatures; at higher (c) and lower (d) TMI/TMG-flow ratios. (Musikhin et al., 2002)

HRTEM shows that lateral size of the QDs are about $3 \mathrm{~nm}$ for the samples lower growth temperature (Fig. 1b). Decreasing the InGaN growth temperature (from $785^{\circ} \mathrm{C}$ to $755{ }^{\circ} \mathrm{C}$ ) results in: a slight increase in QD size; increase of the maximum In concentration in the 
QDs (from 35\% to 50\% for the growth temperature change), and increase of the QD density (from $0.5 \times 10^{12} \mathrm{~cm}^{-2}$ to $3 \times 10^{12} \mathrm{~cm}^{-2}$ for the growth temperature change). Thus, relative change in the growth temperature of the InGaN/GaN QWs at some TMIn flow leads to enhance of the effect of phase separation. Absolute In content at such growth method may be also changed by TMIn/TMGa ratio. For the investigated regimes it even stronger influence indium content than growth temperature (fig 1) which is in a good agreement with results of other works (Bedair et al., 1997; Schenk et al., 1999; Yoshimoto et al., 1991 ).

The key experiment, which can clarify unambiguously the internal nature of the InGaN QW grown at these conditions, is the resonant excitation of PL (Krestnikov et al., 2002a; Krestnikov et al., 2002b).
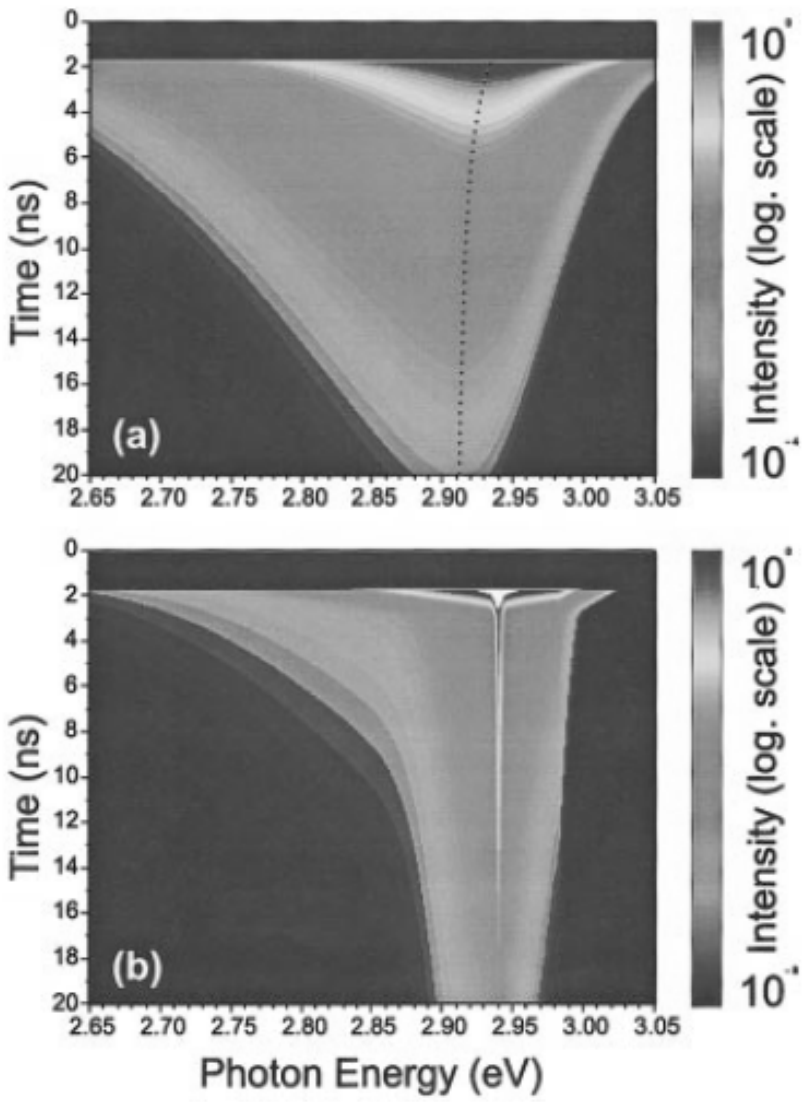

Fig. 2. Time/wavelength plots of PL for nonresonant (a) and resonant (b) excitations for sample grown at $820^{\circ} \mathrm{C}$. White spot corresponds to the scattered laser light. (Krestnikov et al., 2002a)

In the case when the QW is excited, the carrier transfer towards the states having a lower energy occurs, accompanied by fast evolution of the thermalized PL peak. In the case of wurtzite-type strained QWs having a strong built-in piezoelectric field, reduced carrier 
concentration upon the radiative recombination of nonequilibrium carriers must result in reduced screening of the piezoelectric potential, further shifting PL towards the longerwavelength side of the spectra and strongly increasing the PL decay time. Neither of these effects was revealed in the considered case. Nonresonant pulsed excitation results in a broad PL peak, while resonant excitation into the nonresonant PL intensity maximum results in an evolution of a sharp resonant PL peak, having a spectral shape defined by the excitation laser pulse and a radiative decay time close to that revealed for PL under nonresonant excitation. The PL peak position was not shifted with time and no spectral broadening was observed (Fig. 2). This may rule out any importance of the spectral diffusion and gradual weakening of the piezoelectric screening with carrier depopulation, which both should take place in the case of QW. The observed behavior fits exactly the behavior of resonantly excited QDs having a delta-function-like density of state (Paillard et al., 2000) and no exciton or carrier transfer at low temperatures. Observation of a resonantly excited narrow PL line gives clear proof of the QD nature of luminescence in InGaN-GaN samples growth using the described above method.

\subsection{GaN and InGaN interaction with hydrogen}

Before presenting more complex methods of QDs formation we should briefly describe the effect of III-N materials interaction with hydrogen. This effect looks to be the main difference between MOVPE of III-nitrides and classical III-V compounds (Lundin et al., 2005, Yakovlev et al., 2008). The most known manifestation of hydrogen influence on III-N epitaxial process is an insistence of InGaN growth in hydrogen-free ambient (Nakamura et al., 1993) due to suppression of indium incorporation into InGaN layers by hydrogen (Piner et al., 1997). At the same time, hydrogen influences growth and properties of practically all layers in device structures starting from nucleation layer and up to p-contact layer (Lundin et al., 2009a; Lundin et al., 2009b; Yakovlev et al., 2008).

Under typical MOVPE conditions with hydrogen as a carrier gas, GaN epilayer etching occurs, if TMGa supply is switched off (Lundin et al., 2005; Sakharov et al., 2000; Zavarin et al., 2005). It was observed that under any useful reactor conditions GaN epilayer morphology during etching was kept planar allowing subsequent epigrowth. It was proved by a special investigation that GaN growth rate was not influenced by a previous etching. Thus, during one experiment growth and etching rate was measured for a number of reactor conditions (See fig. 1). The detailed study of the effect was a base for development of a kinetic model of hydrogen interaction with the surface of III-nitride layers originally suggested in (Zavarin et al., 2005) and further developed in (Yakovlev et al., 2008).

In accordance with the developed model, GaN interaction with hydrogen during MOVPE is described by the combination of two coupled processes, including reversible decomposition of $\mathrm{GaN}$ by $\mathrm{H}_{2}$ with the formation of free ammonia and adsorbed gallium and reversible evaporation of the adsorbed gallium. The process of gallium desorption that determines the etching rate is strongly temperature-dependent and thus considerable only at high temperatures. GaN decomposition is a fast quasi-equilibrium process of "crystal bulkadsorption layer" interaction which occurs in a wide temperature range and is mostly responsible for the surface coverage with gallium. This two coupled processes influence on III-N epitaxy in different ways. Gallium (and indium) evaporation from the adsorbed layer influence growth rate, alloy composition, peculiarities of initial nucleation during 
heteroepitaxy. Presence of this adsorbed layer with high atom mobility determines masstransport phenomena and degree of equilibrium of material synthesis. Using of these effects in for control of III-N epitaxial process was described in (Lundin et al., 2009b; Lundin et al., 2011a). Below we will concentrate on InGaN/GaN structures fabrication.

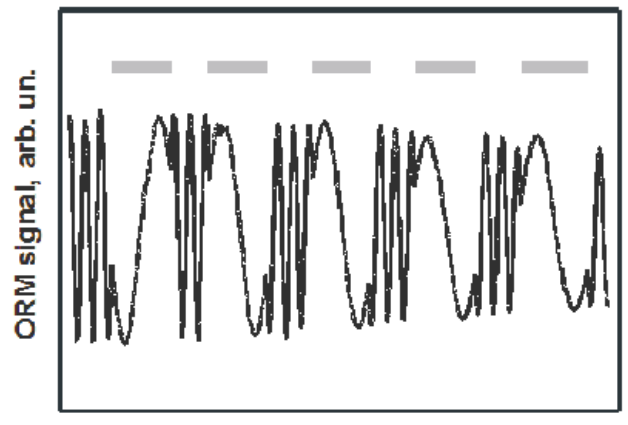

Process time, sec.

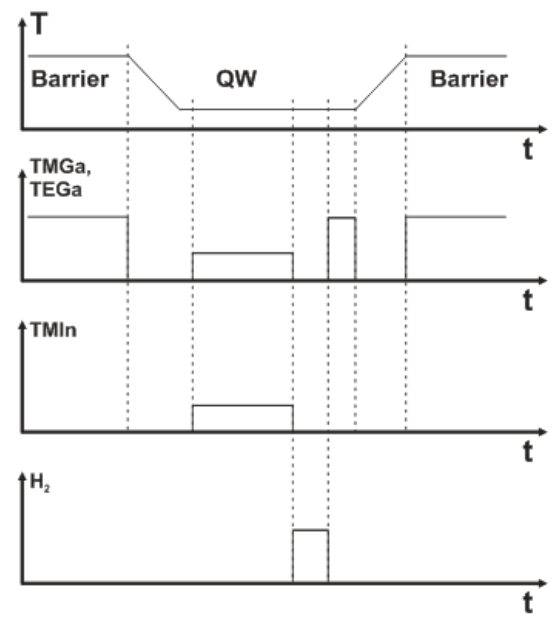

Fig. 3. a - a fragment of as-recorded ORM signal $v$ s time. $\mathrm{b}$ - periods of etching are marked. Flow sequence for one period of InGaN/GaN MQW growth using growth interruptions with hydrogen admixing. (Lundin et al., 2009b)

\subsection{Effect of hydrogen on InGaN QW formation}

As it was mentioned above, using of GI after InGaN QW growth allows to improve luminescence efficiency but blue shift due to indium evaporation during GI sometimes is too high price for quality improvement. In (Sakharov et al., 2000) a modification of simple GI procedure was proposed. It was shown that GI with admixing of a small amount of hydrogen $(\mathrm{GI}+\mathrm{H} 2)$ into the reactor atmosphere results in significantly stronger improvement of material quality (luminescence efficiency) than in the case of GI without hydrogen for the same blue-shift.

Further development of this technology has led to separation of GI+H2 and temperature ramp (Fig. 3). Optimized procedure includes InGaN QW growth, GI+H2 and $2 \mathrm{~nm}$ GaN cap growth at the same temperature, GI without hydrogen for temperature ramp, and growth of $\mathrm{GaN}$ barrier. For MQW formation this procedure should be repeated. Maintaining of the low temperature during GI+H2 reduces blue shift keeping all benefits of InGaN exposition to hydrogen, while during consequent temperature ramp InGaN is already protected by GaN cap layer. It should be noted that the optimal hydrogen content in a carrier gas during $\mathrm{GI}+\mathrm{H}_{2}$ strongly depends not only on other reactor conditions, but also on the reactor design. For example, in a similar blue-LED process for small horizontal and much larger Planetary reactors used it is $0.5-1 \%$ and $20-25 \%$, respectively.

Detailed mechanism of InGaN - hydrogen interaction during GI+H2 is unclear yet. In-N bonds are weaker than Ga-N thus etching is faster for InN component of InGaN alloy. That 
is why InGaN should be grown without hydrogen. During GI+H2 high-quality InGaN decomposes slower than low-quality one. This is a dominant effect for moderate quality structures and it was a driving force for our first experiments on GI+H2. In the works (Liu et al., 2003; Moon et al., 2001) it was shown that the admixing of hydrogen during GIs leads to elimination of the excess of In atoms with InGaN surface and improve structural quality of an InGaN.

Besides, there is a higher-order effect, which becomes dominant for high-quality structures. InGaN interaction with $\mathrm{H}_{2}$ results in the increase of metallic surface coverage at the expense of atoms released from top few nanometers of crystal. Metallic indium partially evaporates, migrates over the surface, and probably re-incorporates back into the crystal volume. Similar process occurs with gallium except the gallium evaporation is low at InGaN growth temperature. Since the InGaN layer grows with the formation of a dense array of the In-rich QDs, which can be partially or completely relaxed in the nonovergrown state, the In atoms migrate to these QDs during GI, which is caused by a decrease of the elastic stresses in them. This assumption agree with the results of work (Karpov et al., 2004), where it was shown that the studied compositions correspond to the immiscibility region in In with considerable phase separation. Thus, a summary effect of these processes (evaporation and migration of In and Ga atoms) leads to a decrease in the sizes of QDs or their complete disappearance. Below there are some more results concerning influence of hydrogen treatment of InGaN QWs on their properties.

In the work (Yong-Tae Moon et al., 2001) it was shown also that the GIs+H2 decrease In content in the upper part of InGaN layer that results in short wavelength shift of the emission. However, in the case of growth thin InGaN QWs effect of the GIs is more complex and leads to modification of microstructure of whole InGaN QW (Tsatsulnikov et al., 2011a). HRTEM images of the thin InGaN layers grown with different duration of the GIs after deposition of the InGaN are shown in the Fig. 4 (a-c).
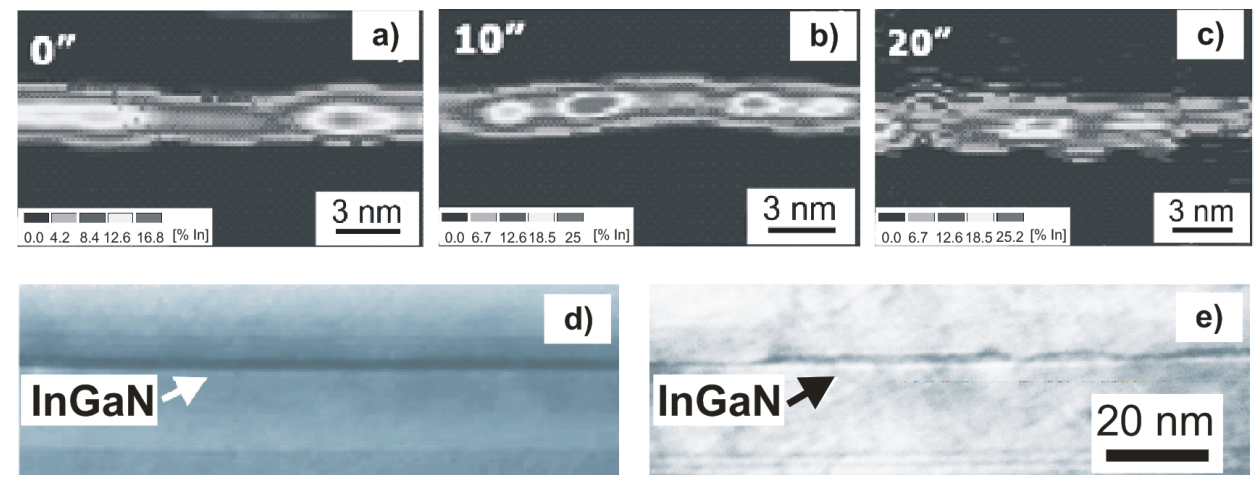

Fig. 4. Color-coded maps of the local In concentration obtained by digital analysis of HRTEM images of the samples grown with GIs having different duration in the hydrogen containing atmosphere (a-c). HRTEM images of the InGaN QWs grown with (d) and without GI (e). (Tsatsulnikov et al., 2011a) 
GIs in the hydrogen containing atmosphere lead to the following changes in the structural properties of the InGaN layers: decrease in the total amount of In atoms in the layer, decrease in sizes of the formed In-rich QDs. A decrease in the total amount of In in the layer and a decrease in the sizes of the QDs is caused by conversion of the InGaN layer in GaN during GI. The joint effect of the decrease in the sizes of QDs and total amount of In lead to the 40-60 meV shift of the emission line to the higher photon energies. Except effect on the properties of the In-rich QDs the GIs resulted in transformation of the continuous InGaN layer to large isolated islands having sizes on several tens of nanometers (Fig. $4 \mathrm{~d}$, e).

Another effect was observed in the case of admixing of hydrogen directly during growth of the InGaN QWs. Distribution of the In atoms in InGaN QWs grown in an atmosphere of nitrogen and with the admixing of hydrogen are shown in Figs. 5. Admixing of hydrogen during the growth leads to a considerable decrease in the density of local In-rich QDs. Comparison of the obtained results with HRTEM images obtained for the structures grown with GIs in the hydrogen containing atmosphere shows that GIs lead to disappearance of already formed QDs while the admixing of hydrogen during the growth of the InGaN initially suppresses the formation of such QDs.
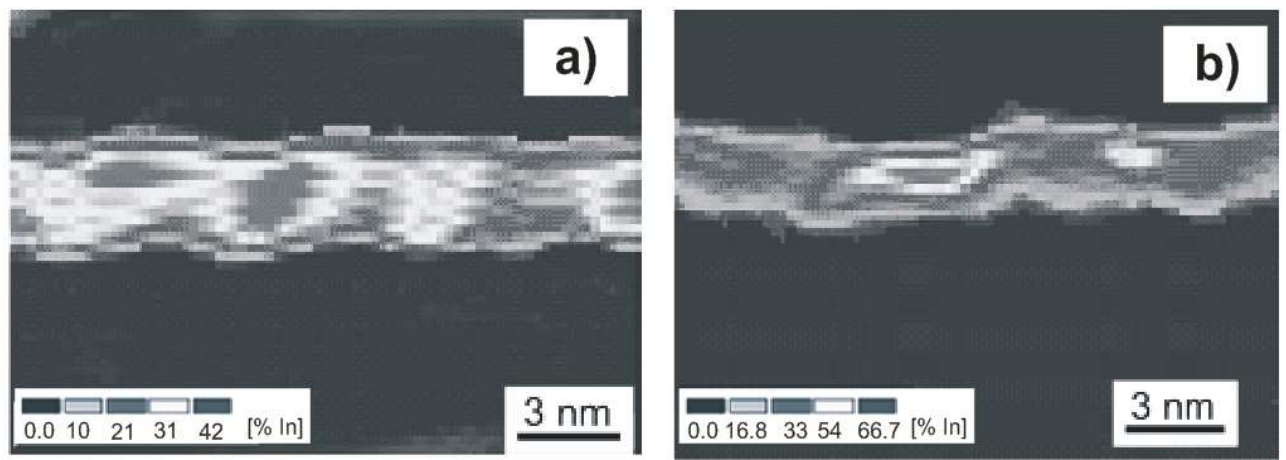

Fig. 5. HRTEM images of the InGaN QWs grown in nitrogen atmosphere (a) and with admixing of hydrogen during growth (b). (Tsatsulnikov et al., 2011a)

The studies of PL spectra upon applying the reverse bias (Tsatsulnikov et al., 2011a) show different behavior of the PL of the structures grown with and without GIs (Fig. 6). Spectrum of the structure grown without GIs has two lines. Line 2 has strong dependence on external bias. Applying the external reverse bias leads to an increase in the band bending, shift of the emission line 2 to shorter wavelengths, and drop in its intensity that indicates that this line is associated with recombination in continuous spectrum. Line 1 does not depended on the bias and can be attributed to the recombination in the local In-rich QDs. Only one line is observed in the PL spectrum of sample grown with GIs. The absence of the shift of this line and a small variation in its intensity at applying of the reverse bias indicate that recombination in this structure proceeds through localized states of QDs in which Stark effect is suppressed. 


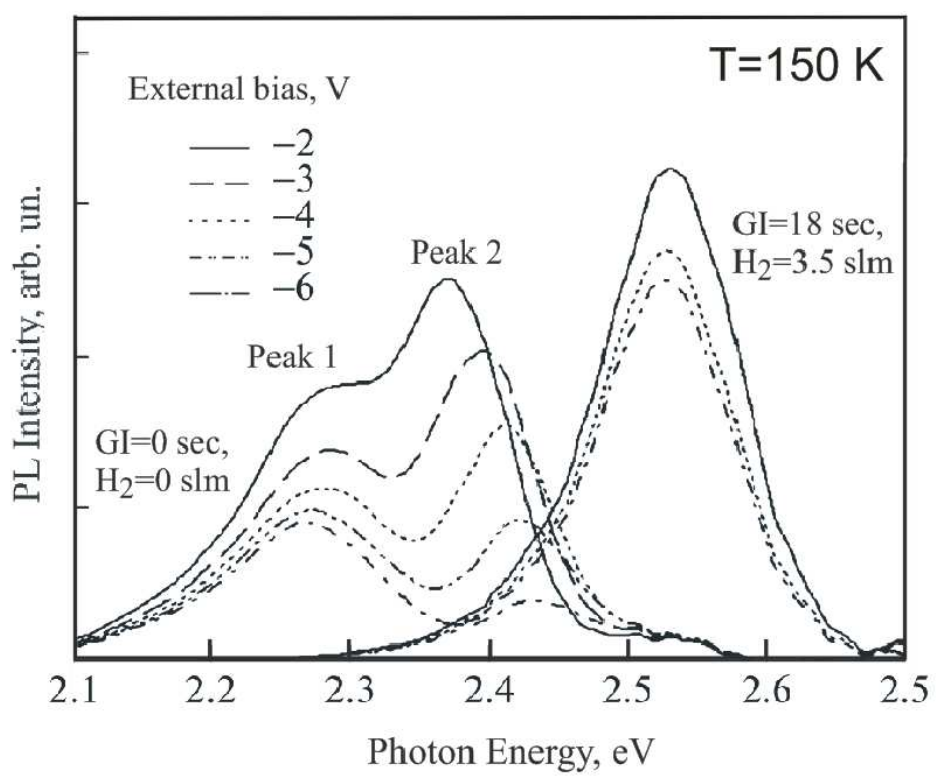

Fig. 6. Photoluminescence spectra of the InGaN/GaN QWs at various values of the reverse bias. (Tsatsulnikov et al., 2011a)

Thus, common investigations show that GI+H2 strongly affect optical and structural properties of the InGaN/GaN QWs.

\subsection{Effect of reactor pressure}

Fig. 7 a, b show HRTEM image of the InGaN MQW structure in which bottom InGaN QW was grown at 100 mbar and following four InGaN QWs were grown at 600 mbar (Lundin et al., 2010). It is seen that continuous InGaN layer is formed at 100 mbar. Increase of the pressure to 600 mbar resulted in formation of the separate QDs. Comparison of the emission properties of the blue LED structures with active region based on the InGaN MQWs grown at pressures in the range of 100-900 mbar shows that increase in the pressure leads to the short wavelength shift of the emission. When comparing structures emitting at different wavelengths, it is more proper to represent the value of the shift in energy units and normalize it to the difference between the energies of emitted photons and the band gap of the barrier layer $(\mathrm{GaN})$. The dependences are shown in Fig. 7 c. It can be seen that, as pressure is increased, the shift of emission to shorter wavelengths becomes larger as the current increases. This effect indicates formation of individual InGaN QDs, which have a significant dispersion on sizes and content which is due to broadening of the spectrum of state. Consequently, as the current is increased, occupancy of QD states with a lower localization energy increases, which leads to an increase in the width of the emission line (Fig. 7 d). In addition, an increase in the pressure leads to variation in the relative value of the shift of the maximum ("blue shift") of the emission wavelength as a function of current (Fig. 7 e). This shift is also related to fluctuations in the In content in the InGaN layers (Martin et al., 1999). 

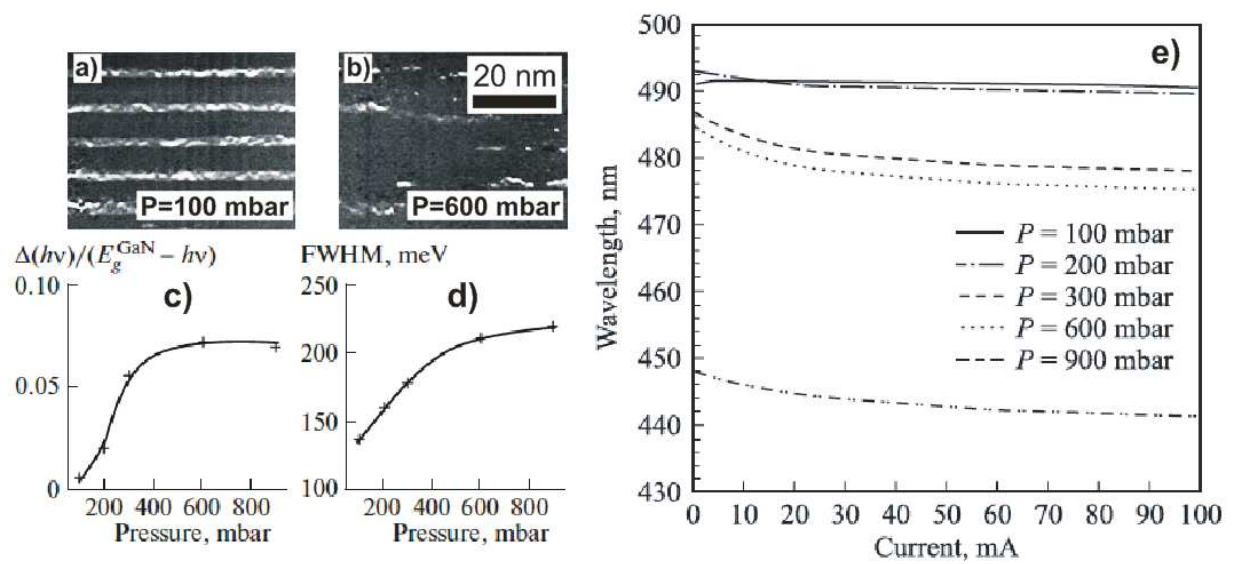

Fig. 7. HRTEM image $(a, b)$, pressure dependencies of the relative shift of the maximum (b) and FWHM (c) of the emission and current dependencies of the maximum of the emission (d) of the InGaN QWs grown at different pressures. (Lundin et al., 2010)

Thus, in the studied series of structures, we observe an anomalous interrelation between the emission wavelength and the line width: structures with a larger wavelength show a narrower emission spectrum and a smaller shift of the emission maximum with current. An increase in the EL wavelength for InGaN/GaN structures is attained by decreasing the growth temperature (which is the generally accepted method of controlling the emission wavelength), whereas structures with a larger wavelength feature a wider spectrum and a larger shift of the emission maximum with current (Martin et al., 1999).

On the other hand, dependence of the external quantum efficiency (EQE) on the pressure has complex character. Increase in the pressure from 100 mbar to 300 mbar leads to increase of the EQE. Following increasing of the pressure to $900 \mathrm{mbar}$ is resulted in decreasing of the EQE. The increase of the EQE, indeed, is due to formation of the separate InGaN QDs that suppress transport of the carriers inside InGaN QW toward defect regions. Future decrease of the EQE is due to decreasing of the carrier confinement in the InGaN QWs due to enhance of the effect of island formation.

\subsection{Composite InAIN/GaN/InGaN QDs}

Besides QD formation via applying of specific growth regimes, QDs can be formed in specially designed structures where this formation is forced by sequence of layers. Novel method of the QD formation based on the growth of composite InAIN/GaN/InGaN QDs was proposed in (Tsatsul'nikov et al., 2010a). This method is based on the formation of the dense array of 3D stressors from wide band gap material InAlN deposited on GaN surface (Fig. 8 a) with following deposition of the narrow band gap InGaN layer. In these structures transformation of the InGaN layer to array of isolated QDs was observed by HRTEM (Fig. 8 b). HRTEM image of the sample with $9 \mathrm{~nm}$ InAlN, $6 \mathrm{~nm}$ GaN and $3 \mathrm{~nm}$ InGaN layers demonstrates complex structure of the InAIN stressors having strong phase separation. This structure is composed of three regions with different morphologies and In and $\mathrm{Al}$ distributions in the growth direction, designated as 1, 2, and 3 in Fig. 8 b. Layer 1 is a $4 \mathrm{~nm}$ 
thick continuous $2 \mathrm{D} \quad \operatorname{In}_{0.02} \mathrm{Al}_{0.98} \mathrm{~N}$ layer with rather abrupt boundaries and constant composition across the layer. Layer 2 is also 2D, but with a nonuniform distribution of In (and $\mathrm{Al}$ ) across its thickness. It comprises two parts. The first part begins at the boundary with the lower $\operatorname{In}_{0.02} \mathrm{Al}_{0.98} \mathrm{~N}$ layer and has a thickness of $2.5 \mathrm{~nm}$. The concentration of In atoms in this part increases in the growth direction from 2 to $17 \%$. The second part of the InAlN layer is $5.5 \mathrm{~nm}$ thick. At the boundary between the first and second parts, the content of In atoms decreases to $10 \%$ and then increases in the growth direction to $22 \%$. Layer 3 is formed on the surface of layer 2. It is an array of 3D islands having the form of truncated pyramids with planar bases and lateral faces with base sizes of 20-30 nm and heights of 4-5 $\mathrm{nm}$. The islands are closely adjacent, without any visible space between the pyramid bases, in agreement with the AFM data.
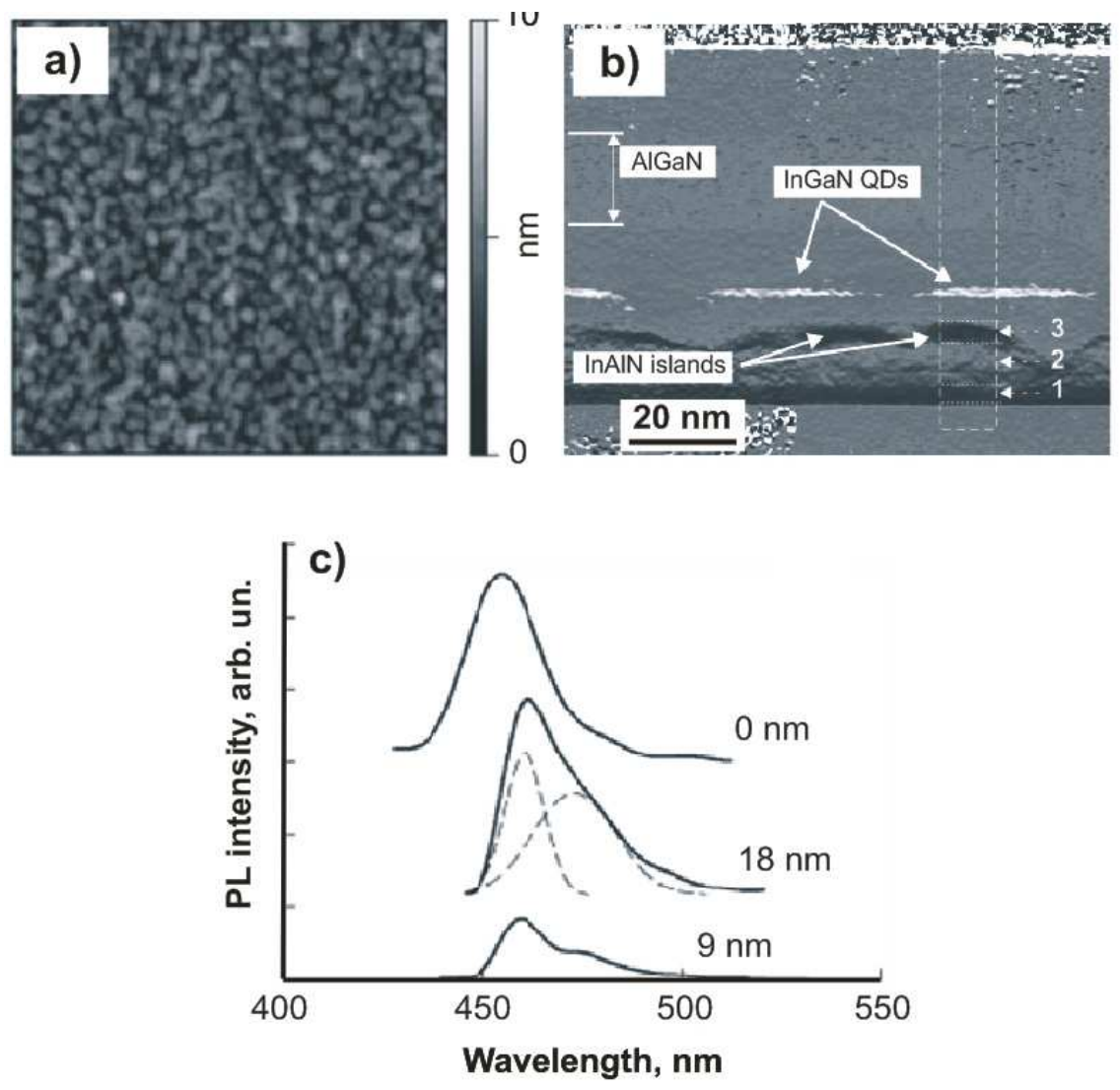

Fig. 8. AFM image (a) of the 9nm thick InAlN stressors, GPA of HRTEM (b) and PL spectra (c) of the InAlN (9 nm) / GaN (6 nm) /InGaN (3 nm) QDs. (Tsatsul'nikov et al., 2010a)

The In content in InAlN islands varies within the range $2-5 \%$ and is constant across the island thickness. Overgrowth of layer 3 with a thin GaN layer, followed by deposition of an InGaN layer, results in formation of the InGaN layer as an array of isolated InGaN islands with an average lateral size of $\sim 30 \mathrm{~nm}$, height of $2.2 \mathrm{~nm}$, and average distance between the 
islands of $\sim 10 \mathrm{~nm}$. The average In content in the islands is $20-22 \%$. Formation of the composite QDs leads to long wavelength shift of the emission and change in the shape of the PL line (Fig. $8 \mathrm{c}$ ).

\subsection{Formation of nanocomposite InGaN/GaN short-period superlattices}

InGaN/GaN short-period superlattices (SPSLs) are an important part of various QD-based LED structures described below. In general, InGaN/GaN SPSL may be grown by consequent growth of InGaN and GaN layers. However, an alternative approach based on InGaN interaction with hydrogen during GI may be used. If after growth of InGaN layer GI with hydrogen admixing is carried out, the described above process results in conversion of InGaN layers at the surface into GaN. In (Kryzhanovskaya et al., 2010; Tsatsulnikov et al., $2011 b)$ InGaN/GaN SLs were formed by altering of growth of thin layers of $\operatorname{In}_{0.1} \mathrm{Ga}_{0.9} \mathrm{~N}$ alloy and growth interruptions when TEGa and TMIn were switched off and carrier gas composition was changed from pure $\mathrm{N}_{2}$ to mixture of $\mathrm{N}_{2}: \mathrm{H}_{2}=7: 3$. Thickness of GaN layers formed by this method was measured by GPA of HRTEM images with accuracy about $1 \mathrm{~nm}$. It was revealed that the thickness of GaN layers formed during GI +H2 is about $1 \mathrm{~nm}$ for 1020 seconds GI duration and saturates at about $2 \mathrm{~nm}$ at 80-160 seconds GI. It means that InGaN conversion process is self-terminated and thickness of $\mathrm{GaN}$ layers in these InGaN/GaN SL is limited to about $2 \mathrm{~nm}$. In [41, 42] thickness of each $\mathrm{In}_{0.1} \mathrm{Ga}_{0.9} \mathrm{~N}$ layer grown between growth interruptions was $2 \mathrm{~nm}$ and duration of GI was 20 seconds which results in SPSL formation confirmed by XRD and HRTEM studies (Fig. 9 a).
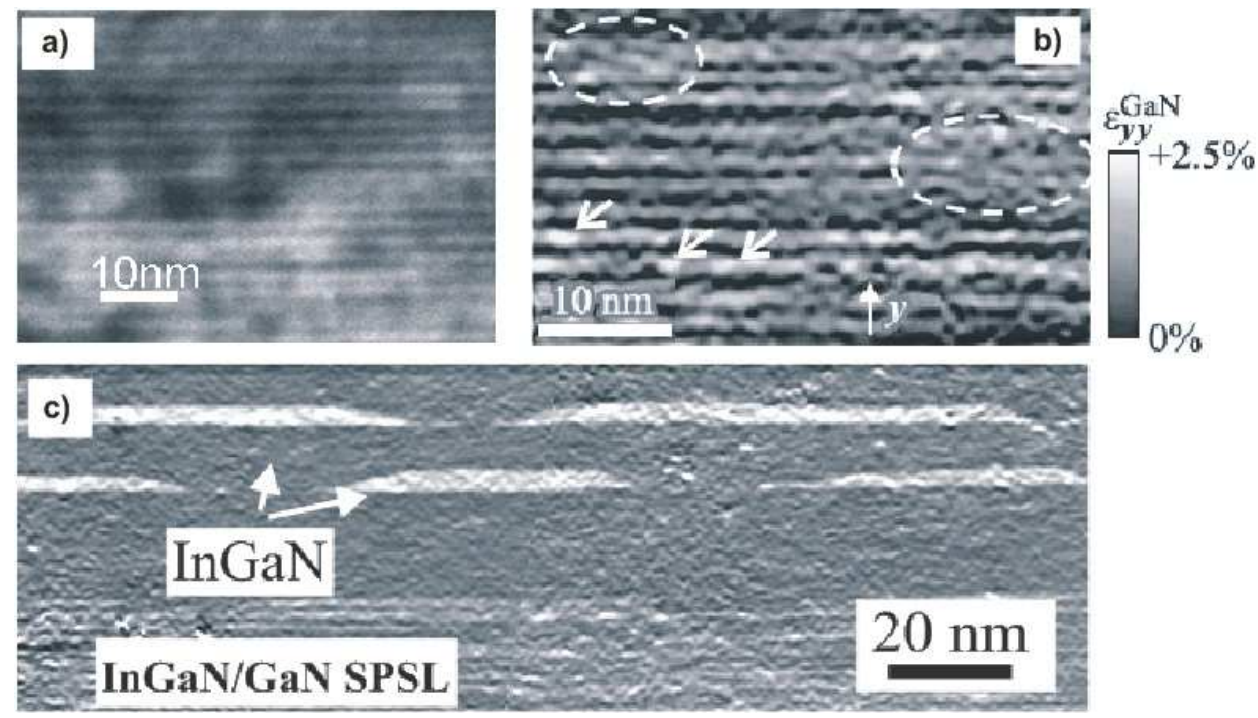

Fig. 9. TEM image (a), GPA of HRTEM (b) of the $1 \mathrm{~nm}$ InGaN/1 nm GaN SPSL. c - HRTEM image of the InGaN/GaN layers deposited on the InGaN/GaN SPSL covered by low temperature GaN barrier. (Kryzhanovskaya et al., 2010; Lundin et al., 2011a)

SPSL period is practically equal to the thickness of individual InGaN layer grown between GIs, and InN mole fraction periodically changes from In content in the InGaN layer to 
nearly zero. On the other hand, geometric phase analysis (GPA) of HRTEM images of these structures has revealed strong non-uniformity in the lateral direction at the nanometer scale (Fig. 6 b). Besides formation of In-rich local areas (arrows on the Fig. 9 b) coalescence of a neighboring InGaN layers is observed (dashed lines on the Fig. 9 b). So, these structures are not classical SPSL but can be considered as layered nanocomposite. It was revealed that deposition of the InGaN layers on the InGaN/GaN SPSL covered by low temperature GaN barrier leads to formation of large separated InGaN QDs (Fig 9 c). These features lead to complex shape of the PL spectrum of the SPSL [41].

TEM investigations of the complex structures containing the described above SPSLs have also shown that no additional dislocations were generated in SPSL in spite of relatively high thickness (up to $120 \mathrm{~nm}$ ). Besides simple periodic SPSLs, this method was applied to the formation of periodical structures with gradually varied parameters as described below.

It should be noted that similar approach was used in (Takeuchi et al., 2009) for AlGaN/AlN SPSL growth but in this case gallium evaporation was induced by ammonia switching off.

\subsection{LED structures based on the InGaN QDs}

Technologies of the growth of InGaN QDs open ways for growth of the LED structures emitting in wide optical range from blue to deep green and, therefore, growth of monolithic white LED structures, containing in active region several InGaN QWs emitting in different optical ranges. QDs make wider optical range of emission due to local increase of the In content, provide better overlapping of electron and hole wave function even in the case of strong build-in piezoelectric fields, suppress carrier transport toward defect regions that leads to increasing of the emission efficiency. On the other hand, InGaN/GaN SPSL can improve injection properties of a LED active region due to effective vertical transport of carriers (Tsatsulnikov et al., 2010b). Thus, combination of the InGaN QDs and InGaN/GaN SPSL in active region allows controlling of the electrical and optical properties of a LED structures. Blue LEDs with active region of LEDs based on the InGaN MQWs confined by InGaN/GaN gradual SPSLs from both sides are described in (Tsatsulnikov et al., 2010b) (Fig. 10 a, c). Variation of indium content in SPSLs along the growth direction was realized by ramping the reactor temperature during SPSL formation procedure. An EQE of these LEDs processed in simple flip-chip geometry reached $30 \%$.

In (Lundin et al., 2011b) deep-green LEDs were reported with an EQE of (8-20)\% in the (560530) $\mathrm{nm}$ range were reported. The combination of $\mathrm{InGaN} / \mathrm{GaN}$ superlattice followed by low temperature GaN (Fig. 10 b, d) was shown to be the key element to increase the electroluminescence efficiency for deep-green range. It was no strain relaxation caused by SPSL in these structures in contrast to reported in (Sakharov et al., 2009), where deep-green emission was realized due to increase of indium incorporation resulting from strain relaxation in InGaN QWs below the active well responsible for light emission.

As was described above applying of the GIs after deposition of the InGaN QWs leads to the QD formation and, therefore, to features in the LED properties. GIs in the hydrogen containing atmosphere effect on the position of the emission line and current dependence of the external quantum efficiency (EQE(I)) of the LED. Applying of the GIs results in short wavelength shift of the emission (Fig. $11 \mathrm{a}, \mathrm{b}$ ) and shift of the maximum in the EQE(I) dependence to low currents (Fig. 11 c, d). These effects are most pronounced for the certain 


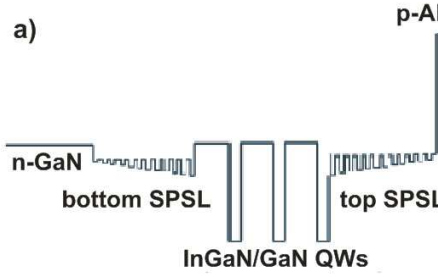

c)

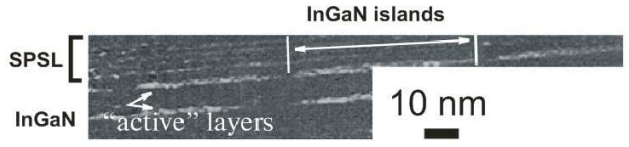

b)
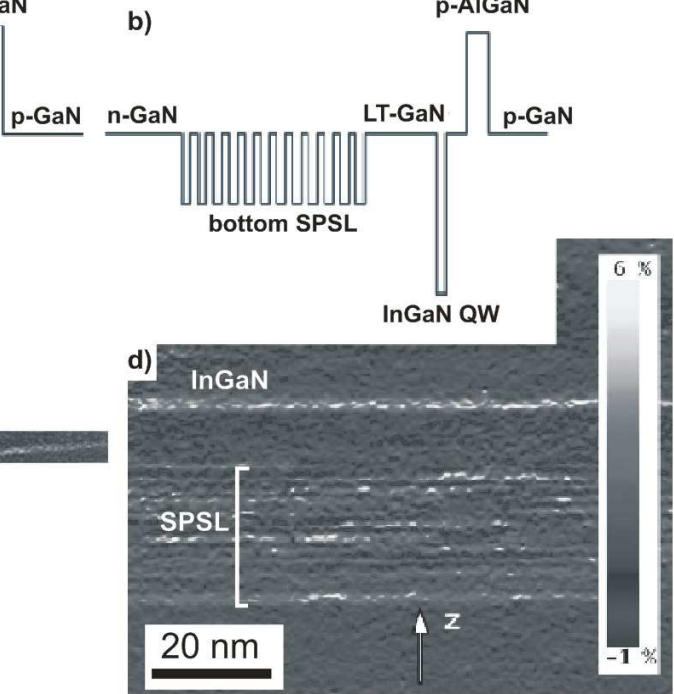

Fig. 10. Schemes $(a, b)$ and HRTEM images $(c, d)$ of the active region of blue $(a, c)$ and deep green $(b, d)$ LED structures based on combination of the InGaN/GaN SPSL and InGaN QWs (a). (Tsatsulnikov et al., 2010b; Lundin et al., 2011b)
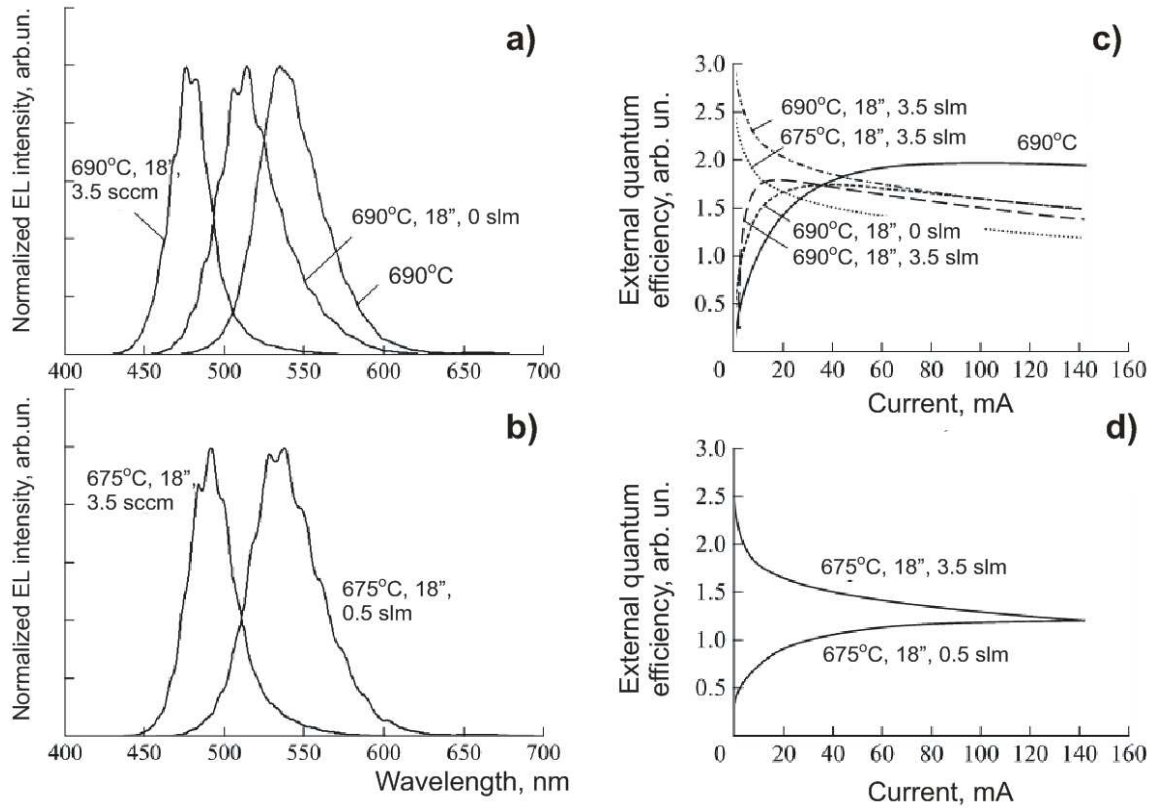

Fig. 11. EL spectra $(a, b)$ and current dependence of the EQE $(c, d)$ of the LED structures grown with GIs having different parameters (growth temperature, duration of the growth interruptions, hydrogen flow). (Tsatsulnikov et al., 2011a) 
growth conditions. It is seen that on the one wafer either a slow monotonic increase in EQE with the current or its rapid increase in the region of low currents with a subsequent drop with the increase in the current are observed. This effect is associated with changes in the density of local In-rich QDs which were observed in the HRTEM images by following manner. Morphological transformation of the InGaN QW to array of QDs leads to variation in the energy spectrum of electrons and holes. An increase in the structural quality of the InGaN QW grown with the use of GIs, a decrease in the density of QDs, and improvement of the carrier transport in such transformed InGaN QWs lead to rapid population of the states of remaining QDs, which causes an abrupt short wavelength shift of the emission line with an increase in the current and a considerable increase in the EQE in the range of low currents (I 5-20 mA for different samples). With further increase in the current, the states of the QDs become completely occupied and, due to effective transport, the fraction of the carriers reach region of dislocations propagating from the buffer layer that leads to a drop in the EQE with an increase in the current. A weak current dependence of the position of the emission maximum at the currents more than $\sim 20 \mathrm{~mA}$ (Tsatsulnikov et al., 2011a) indicates that density of the QDs is not so significant to shift emission wavelength.
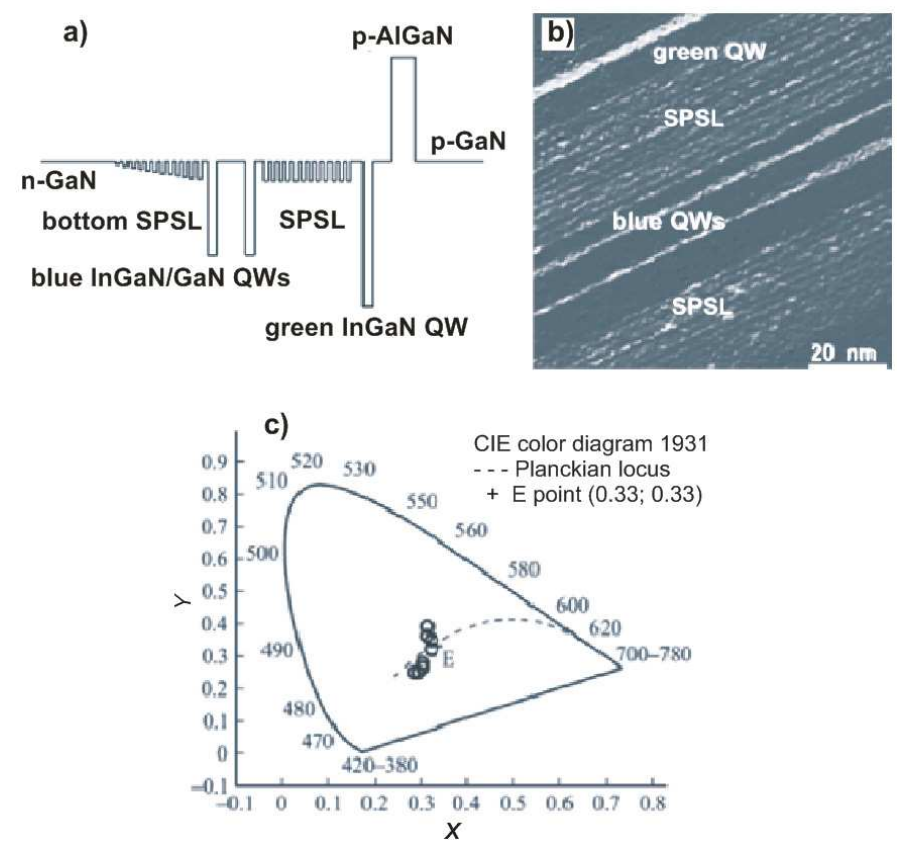

Fig. 12. Scheme (a), HRTEM image (b) of the active region of the monolithic white LED. . c1931 CIE chromaticity diagrams (points show chromaticity coordinates at various currents). (Tsatsulnikov et al., 2010c)

The combination of the InGaN/GaN SPSL with InGaN QWs was used for growth of monolithic white LEDs (Tsatsulnikov et al., 2010c) containing in blue and deep green QWs the active region. The SPSL was used as barrier between the blue and deep green QWs due to it's good vertical carrier transport. Scheme and HRTEM image of the active region of the 
monolithic white LED is shown in the Fig. 12 a, b. Mixing of the emission with wavelengths of $440 \mathrm{~nm}$ and $560 \mathrm{~nm}$ leads to white light emission with color parameters depending on current (Fig. 12 c, circles corresponds to different currents - increase in the current leads to the redistribution of the intensities of the blue and green lines and changes color coordinates). Comparison of the properties of the monolithic white LEDs with GaN and InGaN/GaN SPSL barriers has shown that using of the SPSL allows realization of effective emission from the all active InGaN layers even in the case of significant $(24 \mathrm{~nm})$ distance between blue and green QWs. However, for narrow $(\sim 6 \mathrm{~nm})$ barrier LEDs with GaN barrier show better efficiency. Maximal EQE of $\sim 6-7 \%$ and correlated color temperature (CCT) in the range of 6000 to $10000 \mathrm{~K}$ were demonstrated from these LEDs.

\section{Conclusion}

We have given an overview of the methods of in-situ fabrication of InGaN QDs It was shown that important growth parameters like interaction of InGaN with hydrogen, growth temperature and pressure play key roles in the formation of the InGaN QDs and its properties. Applying of the GIs with hydrogen admixing after InGaN QW growth affects redistribution of In atoms inside QW with modification of sizes of the small nanometer-size In-rich QDs and formation of large isolated islands. Applying of the cycle GIs during growth of a thick InGaN layer allows formation of nanocomposite InGaN/GaN shortperiod superlattices. Increase in the growth pressure at deposition of InGaN QW leads to formation of the separate QDs, modification of emission spectra and changes in the EQE of the LED. InGaN QDs can be formed by growth of special layer sequence in the heterostructures. It was shown that InGaN separate islands are formed in the composite InAlN/GaN/InGaN heterostructures due to increasing of the phase separation effect in the InGaN QW stimulated by InAlN wide bandgap islands. Described methods may be used for fabrication of active regions of light-emitting devices and for growth of other types of epitaxial structures for various applications. These effects must be taken into account during MOVPE of III-Ns, as it can have a strong positive or negative effect depending on the desired structure.

\section{Acknowledgment}

The authors would like thank his colleagues Dr. A. Sakharov, Dr. E. Zavarin, Dr. A. Nikolaev, Dr. V. Sizov, Dr. A. Zakgeim for the fruitful joint investigations. The authors are grateful to Dr. N. Cherkashin for TEM investigations and useful discussions. Authors are indebted to Svetlana-Optoelectronic company for fabrication of LEDs and regional JRC 'Material science and characterization in advanced technologies' for structural characterization.

\section{References}

Bai, J.; Wang, Q.; Wang, T.; Cullis, A. \& Parbrook, P. (2009.) Optical and microstructural study of a single layer of InGaN quantum dots. Journal of Applied Physics, V.105, No.5, (March 2009), pp. 053505-053509, ISSN 0021-8979

Bedair, S.; McIntosh, F.; Roberts, J.; Piner, E., Boutros, K. \& El-Masry, N. (1997). Growth and characterization of In-based nitride compounds. Journal of Crystal Growth, V.178, No.1-2, (June 1997), pp. 32-44, ISSN 0022-0248 
Cho, H.; Lee, J.; Sharma, N.; Humphreys, C. \& Yang. G. (2001), Effect of growth interruptions on the light emission and indium clustering of InGaNOGaN multiple quantum wells. Appl. Phys. Lett., Vol. 79, pp. 2594 - 2596, ISSN 0003-6951

Choi, S.-K.; Jang, J-M.; Yi, S.-H; Kim, J.-A \& Jung, W.-G. (2007). Fabrication and characterization of self-assembled InGaN quantum dots by periodic interrupted growth. Proceedings of SPIE. V.6479, (February 2007), pp.64791F

Daele, B., Tendeloo, G.; Jacobs, K.; Moerman, I. \& Leys, M. (2004). Formation of metallic In in InGaN/GaN multiquantum wells. Appl. Phys. Lett. Vol. 85, pp.4379-4381, ISSN 0003-6951

Gerthsen, D.; Hahn, E.; Neubauer, B.; Rosenauer, A.; Scho“n, O.; Heuken, M. \& Rizzi, A. (2000). Composition Fluctuations in InGaN Analyzed by Transmission Electron Microscopy. Phys. Status Solid Vol. 177, pp.145-155, ISSN: 1862-6300

Hytch, M.; Snoeck, E. \& Kilaas, R. (1998). Quantitative measurement of displacement and strain fields from HREM micrographs. Ultramicroscopy, V.74, No.3, (August 1998), pp.131-146, ISSN 0304-3991

Ji, L.; Su, Y.; Chang, S.; Tsai, S.; Hung, S.; Chuang, R.; Fang, T. \& Tsai, T. (2004). Growth of InGaN self-assembled quantum dots and their application to photodiodes. Journal of Vacuum Science \& Technology. V.A22, (May 2004), pp.792-795, ISSN 0734-2101

Karpov, S.; Podolskaya, N.; Zhmakin, I. \& Zhmakin, A. (2004). Statistical model of ternary group-III nitrides. Physical Review B, V.70, No.23, (December 2004), p. 235203 ISSN 1098-0121

Krestnikov, I.; Ledentsov, N.; Hoffmann, A.; Bimberg, D.; Sakharov, A.; Lundin, W.; Tsatsul'nikov, A.; Usikov,A.; Alferov, Zh.; Musikhin, Yu. \& Gerthsen, D. (2002). Quantum dot origin of luminescence in InGaN-GaN structures. Physical Review B, V.192, (October 2002), pp. 155310, ISSN 1098-0121

Krestnikov, I.; Sakharov, A.; Lundin, W.; Usikov, A.; Tsatsulnikov, A.; Musikhin, Yu.; Gerthsen, D.; Ledentsov, N.; Hoffmann \& A.; Bimberg, D. (2002). Time-Resolved Studies of InGaN/GaN Quantum Dots. Physica Status Solidi, V.192, No.1, pp. 49-53, ISSN 1862-6300

Kryzhanovskaya, N.; Lundin, W.; Nikolaev, A.; Tsatsul'nikov, A.; Sakharov, A.; Pavlov, M.; Cherkachin, N.; Hÿtch, M.; Valkovsky, G.; Yagovkina, M. \& Usov, S. (2010). Optical and structural properties of InGaN/GaN short-period superlattices for the active region of light- emitting diodes. Semiconductors, V.44, No.6, pp.828-834, ISSN 1063-7826

Kumar, M.; Park, J.; Lee, Y.; Chung, S.; Hong, Ch. \& Suh, E.. (2008). Improved Internal Quantum Efficiency of Green Emitting InGaN/GaN Multiple Quantum Wells by In Preflow for InGaN Well Growth. Japanese Journal of Applied Physics V.47, No.2, (2008), pp. 839-842, ISSN 0021-4922

Liu, W.; Chua, S.; Zhang, X. \& Zhang, J. (2003). Effect of high temperature and interface treatments on photoluminescence from InGaN/GaN multiple quantum wells with green light emissions. Applied Physics Letters, V.83, No.5, (August 2003), pp.914-916, ISSN 0003-6951

Lundin, W.; Zavarin, E. \& Sizov, D. (2005). Technical Physics Letters. Influence of the Carrier Gas Composition on Metalorganic Vapor Phase Epitaxy of Gallium Nitride. Vol. 31, No. 4, 2005, pp. 293-294. ISSN: 1063-7850 
Lundin, W.; Sakharov, A.; Zavarin, E.; Sinitsyn, M.; Nikolaev, A.; Mikhailovsky, G.; Brunkov, P.; Goncharov, V.; Ber, B.; Kazantsev, D. \& Tsatsulnikov, A. (2009) Effect of Carrier Gas and Doping Profile on the Surface Morphology of MOVPE Grown Heavily Doped GaN:Mg Layers Semiconductors, Vol 43 No. 7 (July 2009) pp. 963 967. ISSN: 1063-7826

Lundin, W.; Zavarin, E.; Sinitsyn, M.; Nikolaev, A.; Sakharov, A.; Tsatsulnikov, A.; Yakovlev, E.; Talalaev, R.; Lobanova, A. \& Segal, A. (2009), Optimization of III-N heterostructures growth by MOVPE via surface processes control. Proceedings of the 13th European Workshop on Metalorganic Vapour Phase Epitaxy, pp. 9-14 Ulm, Germany, 7-10 June 2009.

Lundin, W.; Zavarin, E.; Sinitsyn, M.; Sakharov, A.; Usov, S.; Nikolaev, A.; Davydov, D.; Cherkashin, N. \& Tsatsulnikov, A. (2010). Effect of pressure in the growth reactor on the properties of the active region in the InGaN/GaN light-emitting diodes. Semiconductors, V.44, No.1, pp.123-126, ISSN 1063-7826

Lundin, W.; Sakharov, A.; Tsatsulnikov, A. \& Ustinov, V. (2011) MOVPE of device-oriented wide-band-gap III-N heterostructures. Semicond. Sci. Technol. Vol. 26 No. 1 (January 2011) p. 014039 ISSN: 0268-1242

Lundin, W.; Nikolaev, A.; Sakharov, A.; Zavarin, E.; Valkovskiy, G.; Yagovkina, M; Usov, S.; Kryzhanovskaya, N.; Sizov, V.; Brunkov, P.; Zakgeim, A.; Cherniakov, A.; Cherkashin, N.; Hytch, M.; Yakovlev, E.; Bazarevskiy, D.; Rozhavskaya, M. \& Tsatsulnikov, A. (2011). Single quantum well deep-green LEDs with buried InGaN/GaN short-period superlattice. Journal of Crystal Growth, V.315, pp.267-271, ISSN 0022-0248

Martin, R.; Middleton, P.; O'Donnell, K. \& Stricht, W. (1999). Exciton localization and the Stokes' shift in InGaN epilayers. Applied Physics Letters, V.74, No.2, (January 1999), pp. 263-265, ISSN 0003-6951

Moon, Y.-T.; Kim, D.-J.; Song, K.-M.; Choi, Ch.-J.; Han, S.-H.; Seong, T.-Y. \& Park, S.-J. (2001). Effects of thermal and hydrogen treatment on indium segregation in InGaN/GaN multiple quantum wells. Journal of Applied Physics, V.89, No.11, (June 2001), pp. 6514-6518, ISSN 0021-8979

Mukai, T.; Yamada, M. \& Nakamura, Sh. (1999) Characteristics of InGaN-Based UV/Blue/Green/Amber/Red Light-Emitting Diodes. Jpn. J. Appl. Phys. Vol. 38 Part 1, No. 7A (July 1999) pp. 3976-3981 ISSN: 0021-4922

Musikhin, Yu.; Gerthsen, D.; Bedarev, D.; Bert, N.; Lundin, W.; Tsatsul'nikov, A.; Sakharov, A.; Usikov, A. Alferov, Zh.; Krestnikov, I.; Ledentsov, N.; Hoffmann, A. \& Bimberg, D. (2002). Influence of metalorganic chemical vapor deposition growth conditions on In-rich nanoislands formation in InGaN/GaN structures. Applied Physics Letters, Vol.80, No.12, (March 2002), pp. 2099-2101, ISSN 0003-6951

Nakamura, S.; Senoh, M. \& Mukai, T. (1993) P-GaN/N-InGaN/N-GaN DoubleHeterostructure Blu-Light-Emitting_Diodes. Jpn. J. Appl. Phys. V 32 No 1 (January 1993), pp. L8-L11. ISSN: 0021-4922

Oliver, R.; Briggs, G.; Kappers, M; Humphreys, C.; Yasin, Sh.; Rice, J.; Smith, J. \& Taylor R. (2003). InGaN quantum dots grown by metalorganic vapor phase epitaxy employing a post-growth nitrogen anneal. Applied Physics Letters, Vol.83, No. 4, (July 2003), pp. 755-757, ISSN 0003-6951 
Paillard, M.; Marie, X.; Vanelle, E.; Amand, T. ; Kalevich, V.; Kovsh, A.; Zhukov, A. \& Ustinov, V. (2000). Time-resolved photoluminescence in self-assembled InAs/GaAs quantum dots under strictly resonant excitation. Applied Physics Letters, Vol.76, No.1, (January 2002), pp. 76-78, ISSN 0003-6951

Piner, E.; Behbehani, M.; El-Masry, N.; McIntosh, F.; Roberts, J.; Boutros, K. \& Bedair, S. (1997), Effect of hydrogen on the indium incorporation in InGaN epitaxial films. Appl. Phys. Lett. Vol. 70 No. 4 (January 1997), pp. 461-463. ISSN 1063-7826

Rosenauer, A.; Kaiser, S.; Reisinger, T.; Zweik, J.; Gebhard, W. \& Gerthsen, D. (1996), Digital analysis of high-resolution transmission electron microscopy lattice images, Optik, Vol. 102, pp.63-69. ISSN: 0030-4026

Sakharov, A.; Lundin, W.; Krestnikov, I.; Bedarev, D.; Tsatsul'nikov, A.; Usikov, A.; Alferov, Zh.; Ledentsov, N.; Hoffmann, A. \& Bimberg, D. (2000). Influence of Growth Interruptions and Gas Ambient on Optical and Structural Properties of InGaN/GaN Multilayer Structures. Proceedings of IWN 2000 4th International Workshop on Nitride semiconductors, pp. 241-243, ISBN 842-6508-23-3, Nagoya, Japan, September 24-27, 2000

Sakharov, A.; Lundin, W.; Zavarin, E.; Sinitsyn, M.; Nikolaev, A.; Usov, S.; Sizov, V.; Mikhailovsky, G.; Cherkashin, N.; Hytch, M.; Hue, F.; Yakovlev, E.; Lobanova, A. \& Tsatsulnikov, A.(2009) Effect of strain relaxation on active-region formation in InGaN/(Al)GaN heterostructures for green LEDs. Semiconductors, v.43, No.6 pp.812-817, ISSN 1063-7826

Schenk, H.; Mierry, P.; Lau“gt, M.; Omne`s, F.; Leroux, M.; Beaumont, B. \& Gibart, P. (1999). Indium incorporation above $800{ }^{\circ} \mathrm{C}$ during metalorganic vapor phase epitaxy of InGaN. Applied Physics Letters, V.75, No.17, (October 1999), pp. 2587-2589, ISSN 0003-6951

Shim, H.; Choi, R.; Jeong, S.; Vinh, L.; Hong, C.-H.; Suh, E.-K.; Lee, H.; Kim, Y.-W. \& Hwang, Y. (2002). Influence of the quantum-well shape on the light emission characteristics of InGaN/GaN quantum-well structures and light-emitting diodes. Applied Physics Letters, V.81, No.19, (November 2002), pp.3552-3554, ISSN 0003-6951

Soh, C.; Liu, W.; Teng, J.; Chow, S.; Ang, S. \& Chua. S. (2008). Cool white III-nitride light emitting diodes based on phosphor-free indium-rich InGaN nanostructures. Applied Physics Letters, V.92, No.26, (January 2008) pp.261909-261911, ISSN 00036951

Sun, Y.; Choa, Y.-H.; Suh, E.-K.; Lee, H.; Choi, R. \& Hahn, Y. (2004). Carrier dynamics of high-efficiency green light emission in graded-indium-content InGaN/GaN quantum wells: An important role of effective carrier transfer. Applied Physics Letters, V.84, No.1, (January 2004), pp.49-51, ISSN 0003-6951

Takeuchi, M.; Maegawa, T.; Shimizu, H.; Ooishi, S.; Ohtsuka, T. \& Aoyagi, Y. (2009), AlN/AlGaN short-period superlattice sacrificial layers in laser lift-off for verticaltype AlGaN-based deep ultraviolet light emitting diodes. Appl. Phys. Lett. Vol. 94, pp. 61117-1 - 61117-3

Tsatsul'nikov, A.; Zavarin, E.; Kryzhanovskaya, N.; Lundin, W.; Saharov, A.; Usov, S.; Brunkov, P.; Goncharov, V.; Cherkashin, N. \& Hytch, M. (2010). Formation of composite InGaN/GaN/InAlN quantum dots. Semiconductors, V.44, No.10, pp.1338-1341, ISSN 1063-7826 
Tsatsulnikov, A.; Lundin, W.; Sakharov, A.; Zavarin, E.; Usov, S.; Nikolaev, A.; Cherkashin, N.; Ber, B.; Kazantsev, D.; Mizerov, M.; Park, H.; Hytch, M. \& Hue, F. (2010). Active region based on graded-gap InGaN/GaN superlattices for high-power 440to 470-nm light-emitting diodes. Semiconductors, V.44, No.1, pp.93-97, ISSN 1063-7

Tsatsulnikov, A.; Lundin, W.; Sakharov, A.; Zavarin, E.; Usov, S.; Nikolaev, A.; Kryzhanovskaya, N.; Synitsin, M.; Sizov, V.; Zakgeim \& A.; Mizerov, M. (2010). A monolithic white LED with an active region based on InGaN QWs separated by short-period InGaN/GaN superlattices. Semiconductors, V.44, No.6, pp.808-811, ISSN 1063-7826

Tsatsulnikov, A.; Lundin, W.; Zavarin, E.; Nikolaev, A.; Sakharov, A.; Sizov, V.; Usov, S.; Musikhin, Yu. \& Gerthsen, D. (2011). Influence of hydrogen on local phase separation in InGaN thin layers and properties of light-emitting structures based on them. Semiconductors, V.45, No.2, pp.271-276, ISSN 1063-7826

Tsatsulnikov, A.; Lundin, W.; Sakharov, A.; Zavarin, E.; Usov, S.; Nikolaev, A.; Kryzhanovskaya, N.; Sizov, V.; Synitsin, M.; Yakovlev, E.; Chernyakov, A.; Zakgeim, A.; Cherkashin, N. \& Hytch, M. (2011). InGaN/GaN short-period superlattices: synthesis, properties, applications. Physica Status Solidi C, V.8, No.7-8, pp. 2308-2310, ISSN 1862-6300

Wang, Q.; Wang, T.; Bai, J.; Cullis, A.; Parbrook P. \&Ranalli, F. (2008). Growth and optical investigation of self-assembled InGaN quantum dots on a GaN surface using a high temperature AlN buffer. Journal of Applied Physics, V.103, No.12, (June 2008), pp.123522-123528, ISSN 0021-8979

Wen, T.-Ch.; Lee, Sh-Ch. \& Lee W-I. (2001). Light-Emitting Diodes: Research, Manufacturing, and Applications. Proceedings of SPIE, V.4278, (May 2001), pp. 141149

Yakovlev, E.; Talalaev, R.; Kondratyev, A.; Segal, A.; Lobanova, A.; Lundin, W.; Zavarin, E.; Sinitsyn, M.; Tsatsulnikov, A. \& Nikolaev, A. (2008). Hydrogen effects in III-nitride MOVPE. Journal of Crystal Growth. V.310, pp. 4862-4866. ISSN 0022-0248

Yong-Tae Moon, Dong-Joon Kim, Keun-Man Song, Chel-Jong Choi, Sang-Heon Han, TaeYeon Seong, Seong-Ju Park. (2001). Effects of thermal and hydrogen treatment on indium segregation in InGaN/GaN multiple quantum wells. Journal of Applied Physics. Vol. 89, No.11, (June 2001), pp. 6514-6518, ISSN 0021-8979

Yoshimoto, N.; Matsuoka, T.; Sasaki, T. \& Katsui, A. (1991). Photoluminescence of InGaN films grown at high temperature by metalorganic vapor phase epitaxy. Applied Physics Letters, V.59, No.18, (October 1991), pp. 2251-2253, ISSN 0003-6951

Zavarin, E.; Sizov, D.; Lundin, W.; Tsatsulnikov, A.; Talalaev, R.; Kondratyev, A. \& Bord, O. (2005), In-Situ investigations of GaN chemical unstability during MOCVD. Proceedings of the EUROCVD-15, vol. 2005-09, Bochum, Germany, 2005, Electrochemical Society, NJ, USA, pp. 299-305 


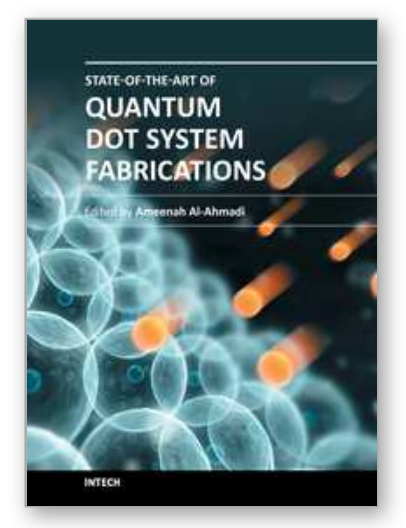

\author{
State-of-the-Art of Quantum Dot System Fabrications \\ Edited by Dr. Ameenah Al-Ahmadi
}

ISBN 978-953-51-0649-4

Hard cover, 172 pages

Publisher InTech

Published online 13, June, 2012

Published in print edition June, 2012

The book "State-of-the-art of Quantum Dot System Fabrications" contains ten chapters and devotes to some of quantum dot system fabrication methods that considered the dependence of shape, size and composition parameters on growth methods and conditions such as temperature, strain and deposition rates. This is a collaborative book sharing and providing fundamental research such as the one conducted in Physics, Chemistry, Material Science, with a base text that could serve as a reference in research by presenting up-todate research work on the field of quantum dot systems.

\title{
How to reference
}

In order to correctly reference this scholarly work, feel free to copy and paste the following:

A.F. Tsatsulnikov and W.V. Lundin (2012). Stimulated Formation of InGaN Quantum Dots, State-of-the-Art of Quantum Dot System Fabrications, Dr. Ameenah Al-Ahmadi (Ed.), ISBN: 978-953-51-0649-4, InTech, Available from: http://www.intechopen.com/books/state-of-the-art-of-quantum-dot-systemfabrications/stimulated-formation-of-ingan-quantum-dots

\section{INTECH}

open science | open minds

\section{InTech Europe}

University Campus STeP Ri

Slavka Krautzeka 83/A

51000 Rijeka, Croatia

Phone: +385 (51) 770447

Fax: +385 (51) 686166

www.intechopen.com

\section{InTech China}

Unit 405, Office Block, Hotel Equatorial Shanghai

No.65, Yan An Road (West), Shanghai, 200040, China

中国上海市延安西路65号上海国际贵都大饭店办公楼 405 单元

Phone: +86-21-62489820

Fax: +86-21-62489821 
(C) 2012 The Author(s). Licensee IntechOpen. This is an open access article distributed under the terms of the Creative Commons Attribution 3.0 License, which permits unrestricted use, distribution, and reproduction in any medium, provided the original work is properly cited. 